\title{
Effectiveness of Prenatal and Postnatal Instruction in Postpartum Care
}

DOROTHY D. PETROWSKI, RN, PhD

An experimental study using a random sample of 40 staff patients in two inner-city maternity hospital clinics was conducted to determine the optimum time to teach postpartum content to maternity patients. Instruction of special postpartum content, or the lack of it, to prenatal and postpartum patients yielded no statistical difference in the results. However, the methodology used in patient instruction and the measurement of its effectiveness warrants scrutiny.

The three major aspects of teaching related to postpartum and newborn information given to maternity patients are (1) timing of instruction, (2) repetition of instruction, and (3) readiness to learn.

At the heart of any educative process is the communication of knowledge and/or skills to a student in such a manner that she will retain what she learns and transfer it to appropriate situations in the future. ${ }^{1}$ Thus, the crucial problem in any learning experience is how to facilitate the transfer of knowledge to long-term memory. ${ }^{2}$

A possible contributor to retention of knowledge is the timing of presentation to the learner. Underwood and Richardson found that sequencing of nonsense syllables was not related to serial position. ${ }^{3}$ Hungerford studied the effect of varying time of presentation of oral directions on the subjects' recall and retention in a learning situation. ${ }^{4}$ An analysis of variance identified significant interaction between ability, sex, and the experimental treatment.

Repetition of instruction is also a factor in retention of knowledge. Ebbinghaus concluded that a suitable distribution of repetitions is decidedly more advantageous than the massing of them at a single time. ${ }^{5}$ Underwood, et al., found distributed practice, i.e., repetition, facilitates both recall and relearning with a list of syllable-adjective pairs. ${ }^{6}$ Distributed practice is effective because the learner needs time to put the material into perspective and time to contemplate the content, ${ }^{7}$ and is important because it increases stability and clarity in the cognitive structure. $^{8}$

The third item needed to retain knowledge is readiness. Redman states, "Learning is most effective when an individual is ready to learn, that is when he feels a need to know something." 9 Sometimes readiness comes quite naturally and the nurse need only encourage it. Other times the nurse needs to use direct intervention, so that the desired behavior occurs. One aspect of postpartum instruction included care of the newborn. Tanner stated that some time after the sixth month of pregnancy a woman shows a readiness for the caretaking relationship with her baby, and this continues and increases in the third trimester. ${ }^{10} \mathrm{On}$ the other hand, Adams pointed out that the period of pregnancy had not been a time of active interest in infant care for the subjects in her study. ${ }^{11}$

Physical comfort contributes to readiness to learn for the patientlearner. A workable definition of pain might be, "Pain is whatever the experiencing person says it is and exists whenever he says it does." 12 The learning environment for the maternity patient must be free from pain and the sedative effects of drugs if she is to benefit from the nurse's instruction.

The last trimester of pregnancy, especially the waiting time in clinic, might be a fruitful time to introduce postpartum content. An experimental study using a random sample of 40 staff patients in two maternity hospitals was conducted to determine the optimum time to teach postpartum content 
to maternity patients. The main objectives of the study were to determine if 1) primigravidas taught special postpartum information in their prenatal period retain more than if taught in the postnatal period, and 2) an improved teaching-learning process occurs when postpartum information is given in the prenatal phase and retaught in the postpartal phase, i.e., repetition of instruction. A subobjective was to monitor the patient's state to decide if she were more comfortable when instructed in the prenatal or the postnatal state.

\section{Methodology}

Subjects selected for the study were primiparas, staff patients of two inner-city hospital clinics in Washington, D.C., educated in the United States, who delivered healthy, normal infants (not less than five pounds). Fifty-six subjects who met the first three criteria were randomly assigned to one of four treatment groups. Thirtysix subjects completed all testing. Twenty subjects did not complete the test for various reasons and were eliminated from the study. A goal of 40 subjects, rather than 56 , was then accepted, and the four needed subjects were selected nonrandomly. Although all subjects had normal babies, five who required cesarean sections were included because it was felt that this type of surgery would not interfere with the instruction and testing done in this study. There were four treatment groups of 10 subjects.

The design for this research study was a $2 \times 2$ factorial with the intelligence factor controlled by the covariance technique. The independent variables were related to the timing, repetition and readiness for postpartum instruction, and instruction, or the lack of it, of special postpartum content to prenatal or postpartum patients. The dependent variable was the acquisition of knowledge from instruction in postpartum and newborn care.

September/October 1981 JOGN Nursing

Table 1. Analysis of Covariance for the Vocabulary and Criterion Measure Scores.

\begin{tabular}{lccc}
\hline Source of Variation & Degrees of Freedom & Mean Square & \multicolumn{1}{c}{$F^{*}$} \\
\hline Prenatal Instruction & 1 & .20 & .05 \\
Postnatal Instruction & 1 & 9.71 & 2.18 \\
Interaction & 1 & .74 & .17 \\
Error & 35 & 4.45 & \\
\hline
\end{tabular}

${ }^{*} F_{.90,1,35}=2.88$ (Critical $F$ value at $p 0.05=2.88$ )

Four instruments were used in the study. The Peabody Picture Test, ${ }^{13}$ with a reliability of 0.93 for this study population, was used to estimate the subjects' educational level. The other three instruments, developed for the study were 1) the Instructional Packages (four cassette recordings - Care of the Umbilical Cord and Navel, Burping or Bubbling a Baby, Perineal Care, and Rest, Activity and Exercise-with each tape accompanied by 13 pictures on $5 \times 8$ inch cards; there are alternate forms, I and II), 2) the Criterion Measure, and 3) a comfort scale. The Instructional Packages contained the special postpartum study instruction. The content validity of the Instructional Packages was judged by a panel of experts in nursing and related fields. A multiple choice test of 20 questions with four alternative answers was developed from the information in the Instructional Packages. A self-description by subjects and an evaluation by the nurse were recorded on a 5-point comfort scale, used to ascertain if the subject was more comfortable during instruction as a prenatal or postnatal subject. In addition, complaints of pain and administration of analgesics were recorded from the patient's record in the eight hours prior to instruction.

After a pilot study, the Peabody Picture Vocabulary Test was administered to all subjects in the third trimester of their pregnancy in a clinic situation to evaluate their educational competence (or intelligence). Half of the subjects, that is, Groups 1 and 2, received the Instructional Package, Form I, in the last trimester of pregnancy in the clinic. A third group received the Instructional Package, Form I, on the hospital ward from their first to fourth day postpartum. In addition, the first group was re-instructed on the hospital ward with Instructional Package, Form II. This was the only group to receive the instruction twice. (The Alternate Form II was developed only to make the repeated instruction a more interesting experience for this group of patients.) Group 4, the control group, received no instruction at any time in the study, unless subjects requested it after they had had the criterion measure, and most subjects did make the request. All subjects received the criterion measure, considered a test of long-term retention, in their homes from the fifth to the 13th day postpartum, that is, essentially the second week postpartum. Data collection took approximately seven months.

\section{Results}

An analysis of variance was done on the 20-point test or criterion measure (dependent variable) and the vocabulary test (covariate) for the four groups prior to the analysis of covariance. To test the equivalence of mean performance on the vocabulary and criterion test the Hartley's $F_{\max }$ Test was performed, and the equivariance assumptions were met. The final results of the analysis of variance were not statistically significant.

An analysis of covariance was applied in which the test scores were adjusted to remove the por- 
tion of residual variance predictable from the vocabulary of the subjects. All of the required assumptions underlying the analysis of covariance were tested prior to its use. The results of this analysis of covariance are presented in $\mathrm{Ta}$ ble 1 . None of the null hypotheses relating to the research hypotheses for the analysis of covariance were rejected at the 0.05 level of significance using a directional test of the hypothesis. However, the obtained $F$ value of 2.18 for the special postnatal instruction during the postpartum cycle clearly approaches the 2.88 critical value of $F$ necessary to attain significance. Alternative explanations for the obtained result could be sample size, the particular criterion measure used, and unknown causes.

No subjects instructed prenatally received pain medication in the eight hours prior to instruction, but $55 \%$ of the subjects instructed postnatally received an analgesic within the eight hours prior to instruction. Nurses generally saw subjects as slightly more comfortable than the subjects rated themselves.

\section{Discussion}

The results of this study on the timing, repetition and readiness for learning and the observations of the researcher emphasize the pressing need for intensified research and development of effective patient teaching methods as a primary means of preventive health care. The subjects of this study were not typical of the general population, but certainly representative of a substantial portion of the inner-city core population. All were young (median age 19.3), predominantly single, blacks who lived mainly in large family groupings (range of two to 12 members in the household with a mean of 5.6). Most stated that their mothers were the persons closest to them; i.e., a matriarchal subculture. The educational attainment was relatively low; half of the subjects had not graduated from high school. The mean score on the criterion measure of the four groups in the study was only 9.9 out of a possible 20. Many experts in maternity care would suggest that these subjects should know, as a minimum, the information taught in this study to care adequately for themselves and their infants. In any case, instruction in postpartum care should not be left to happenstance.

The study has limitations because patients could not be denied whatever regular postpartum and newborn instruction the two study hospitals gave their patients. Thus, the instruction given to subjects in this study to test learning is designated as special.

The fact that this study utilized a particular methodology that was original and scientific in the measurement of patient instruction is noteworthy. In view of the findings, the following recommendations for further research are made:

1. The study should be replicated using variables other than timing, such as motivation or patient participation, in planning maternity instruction.

2. Experiments could be conducted using different teaching techniques. For example, instruction of maternity patients may lend itself particularly well to teaching by demonstration because manual skills, in addition to cognitive understanding, are inherent in maternity instruction.

3. It is possible that an entirely different avenue of approach to instruction would produce other results. For example, another responsible family member might be involved in the maternity instruction.

4. The pain factors associated with teaching maternity patients should be researched. A postpartum patient may or may not respond better to instruction if given an analgesic within four hours prior to instruction. Patients are a class of subjects required to learn under the handicap of pain and drug effects.

5. Instruction might be made more effective by revising nursing textbooks to include more maternity care in the home setting by the community health nurse, programming client participation in instruction, teaching clients in the evenings or on Saturdays when the "significant other" is available, and preparing validated tests for client instruction.

6. Because much of the content given to patients does not change drastically from one year to the next, validated criterion measures to test patient retention of the teaching could be developed. Then those patients requiring special attention could be helped. Maternity and diabetic teaching are two areas in which this could be feasible. ${ }^{14,15}$

\section{Nursing Implications}

Most maternity nursing textbooks emphasize the hospital stay, although the patient is at home during most of her maternity cycle. Texts should include more information on the characteristics and needs of mothers and infants after hospital discharge to enable nurses to prepare mothers for continuing care without supervision.

The nurse should make a determined effort to include the client's "significant other" in the instruction, especially if the client is very young. The nurse could visit the home in the evening hours or on Saturdays. Several Visiting Nurse Associations, such as the one in Madison, Wisconsin, have established two shifts, day and evening. ${ }^{13}$ Improved maternity patient instruction certainly is in the area of preventive health care, and preventive obstetric health care is a key factor in healthy pregnancies, birth, and parenting.

\section{References}

1. Combs AW, Syngg D: Individual Behavior. New York, Harper \& Brothers, 1959, pp 190-209

2. Travers RMW: Educational Psychology. New York, Macmillan, 1972, pp 277-282

3. Underwood BJ, Richardson J: The influence of meaningfulness, 
intralist similarity, and serial position on retention. J Exp Psychol 52:119-125, 1956

4. Hungerford WE: Effects of Varying Time of Presenting Verbal Directions on Recall and Retention. (Doctoral Dissertation, East Texas State University) Ann Arbor, Michigan, University Microfilms, 1972, No. 72-74, 270

5. Ebbinghaus H: Memory-A Contribution to Experimental Psychology. New York, Dover Publications, 1964, p 39 (Published in German in Leipzig, 1885 and translated by Ruger HA and Bussenius CE, Columbia University, 1913)

6. Underwood BJ, et al.: Studies of distributed practice-Some conditions which enhance retention. J Exp Psychol 64:335-363, 1962

7. Divesta FJ, Thompson GC: Educational Psychology-Instructional and Behavioral Change. New York, Appleton-Century-Crofts, 1970, pp 287-289

8. Ausubel DP: Educational Psychology-A Cognitive View. New
York, Holt, Rinehart \& Winston, 1968, pp 83, 273-275

9. Redman BK: The Process of Patient Teaching. Third edition. St. Louis, CV Mosby 1976 p 49

10. Tanner LM: Developmental tasks of pregnancy, Current Concepts of Clinical Nursing, Vol 2. Edited by EH Anderson. St. Louis, CV Mosby 1969 pp 204-209

11. Adams M: Early concerns of the primigravida mothers regarding infant care activities. Nurs Res 19:72-77, 1963

12. Siegele DS: The gate control theory. Am J Nurs 74:498, 1974

13. Dunn LM: Peabody Picture Vocabulary Test-Manual. Circle Pines, Minnesota, American Guidance Service, Incorporated, 1965

14. Wisconsin Community Health Nurses Organization, Minutes of a Meeting, October 31, 1978

15. Redman BK: Diabetes education: Its strengths, weaknesses, and prospects. Diabetes Educator 3:69, 1977-1978

16. Aukschun MN Sr: Discharge planning in diabetes education.
Diabetes Educator 3:22-23, 19771978

Address correspondence to Dorothy Petrowski, RN, PhD, School of Nursing, The University of Wisconsin, PO Box 413, Milwaukee, WI 53201.

Dorothy D. Petrowski is the coordinator for evaluation of the undergraduate curriculum and associate professor in the University of Wisconsin's School of Nursing in Milwaukee. Dr. Petrowski has served as chairperson of the Masters Program in Community Health Nursing at Catholic University of America in Washington, D.C., and assisted in the development of a nurse practitioner program at West Virginia University in Morgantown. Dr. Petrowski attended Loyola University (BSN) in Chicago, University of Michigan (MPH) in Ann Arbor, and University of Maryland $(P h D)$. A member of ANA, APHA, NLN, and Wisconsin Community Health Nurses Organization, Dr, Petrowski has written Clinical Nursing for Community Health Practice, which is in press.

\section{TAKE A DAY OFF FROM SMOKING NOVEMBER 19, 1981}

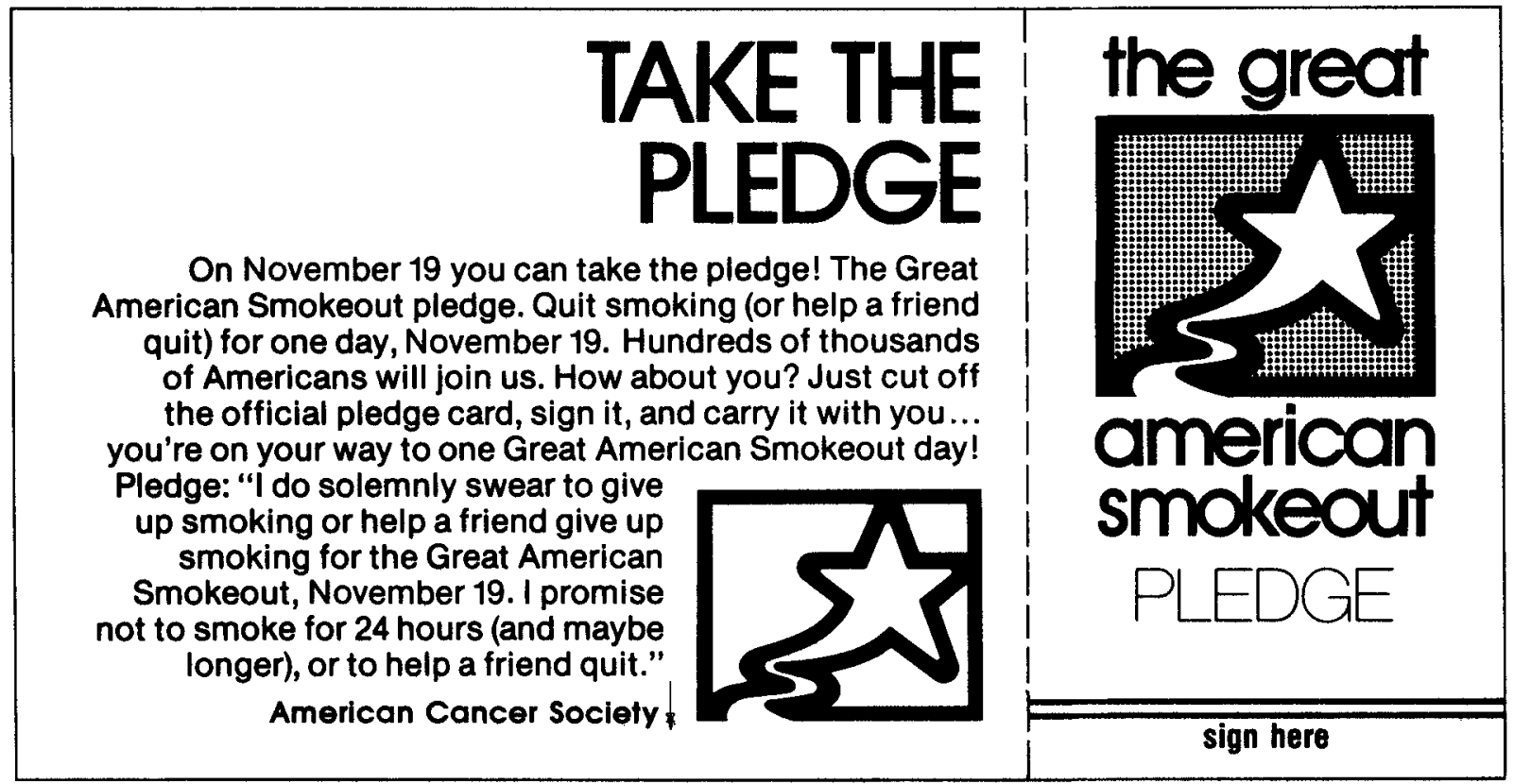

